\title{
Launching a Graduate Education Course in Educational Neuroscience
}

STEPHEN CAMPBELL

Simon Fraser University

An increasing number of education facilities and faculty members are working in a new area of educational research known as educational neuroscience. A key factor for the success and future viability of educational neuroscience concerns training highly qualified personnel who can assist in establishing this new area and move it forward. As an educational researcher currently instituting an educational neuroscience laboratory, this issue is no longer solely an academic interest; it has become a pressing practical matter of vital concern. This discussion paper reports and reflects on the design, approval, implementation, conduct, and reception of a new graduate course, entitled "Educational Neuroscience: Background, Theories, and Methods," offered for the first time in the 2005-2006 academic year.

\section{Introduction}

This paper discusses objectives, motivations, and implementation of a new graduate course entitled "Educational Neuroscience: Background, Theories, and Methods."* It provides rationale for designing and offering this course.

Augmenting qualitative studies of teaching and learning with quantifiable observations of brain and brain behavior, educational neuroscience offers a new approach to scientifically based research in education (NRC, 2000; 2002). One objective in designing and offering a graduate course in educational neuroscience is to help to expand the horizons of educational research by preparing highly qualified personnel in this area (e.g., Eisenhart \& DeHaan, 2005). It also serves to meet a pressing need for such expertise in the author's educational neuroscience laboratory <www.engrammetron.net>. Overall, this new course has been launched to provide new vistas for graduate students in education.

As with any new area of research, as will be discussed further below, educational neuroscience is

\footnotetext{
* For those students interested in taking this course, note that it is being offered again, with the modified title "Educational Neuroscience: Theories, Methods, and Applications" in the Faculty of Education at SFU this Summer Semester, 2008. Please contact Professor Campbell, email, sencael@,sfu.ca, or telephone (778) 782-3630, for details.

(C) Copyright 2008. The author, Stephen Campbell, assigns to the SFU Educational Review the right of first publication and educational and non-profit institutions a non-exclusive license to use this document for personal use and in courses of instruction provided that the article is used in full and this copyright statement is reproduced. Any other usage is probibited without the express permission of the author.
} 
not emerging in a vacuum. The preliminary task of this course is to familiarize students with scientific, technical, social, and educational contexts through which the new area of educational neuroscience has begun to emerge An important preliminary objective of this course is to provide students with opportunities to become familiar with this context, and to critically engage it for themselves.

Another important objective is to introduce students to theoretical issues that can both help relate and distinguish the common and diverse interests of cognitive and educational neuroscience. Such relations and distinctions must stand up to scrutiny if students are to feel confident and clear about committing themselves any further to this emerging new area of educational research.

With adequate background and theory in place, perhaps the single most important objective of this course is to provide students with project-oriented, hands-on laboratory experience using methods for integrating the study of mind, brain, and behavior. Methods are not limited to EEG. Other methods for observing behavior, such as eye-tracking (ET), electrocardiography (EKG), and galvanic skin response (GSR) are to be used. Although there was not sufficient opportunity in the first offering to prepare any varied laboratory component for this course, students enrolled were provided with opportunities to learn some principles of experimental design, and to participate in pilot studies that were designed and conducted by the author in his laboratory.

An initial objective for this paper was to report upon the teaching of this course from within a framework of action research (e.g., McNiff \& Whitehead, 2002). In so far as action research is seen "not as a set of concrete steps but as a process of learning from experience, a dialectical interplay between practice, reflection and learning" (ibid., p. 13), this aim is fulfilled. Accordingly, this paper does not portend to present the results of any formal research process. Rather, it provides rationale for proposing such a course, and a reflective narrative on selected aspects of its first offering (cf., Richardson, 1994).

\section{Background}

It is no surprise that educational researchers interested in systems neuroscience have typically cut their teeth in the neurosciences through collaborations with neuroscientists. This collaborative approach can be both fruitful and frustrating. Fruitful in the sense that whenever different mindsets and methods converge, there is bound to be some good come of it, and there is no reason to expect this basic truism will ever change. Neuroscientists have developed powerful and promising new methods for researching brain and brain behavior. The fast growing area of cognitive neuroscience has been coupling these developments with studies in cognition that hold great interest to educators. Students were particularly interested in understanding in what ways.

Collaborations with neuroscientists, even of the cognitive ilk, as fruitful as they may be, can also be frustrating to educational researchers. Firstly, it is typically neuroscientists who hold the keys to and determine the priorities for operating expensive facilities for studying brain and brain behavior. It is only natural that research in these facilities is first and foremost subject to the priorities of neuroscience rather than those of education. Secondly, some philosophical perspectives and theoretical frameworks of cognition and learning of neuroscientists can be at odds with those of educational researchers.

A second concern is not particularly frustrating from a theoretical or philosophical point of view. A sound critical mindedness can only welcome and engage in such differences. It can become frustrating, however, when experimental design is determined and access is limited by neuroscientists primarily subject to the predilections of the neurosciences.

Because the intrinsic fruitfulness of collaboration between cognitive neuroscientists and educational researchers will indubitably outweigh these frustrations, ways are being found to overcome them. Some cognitive neuroscientists are bringing their methods to bear on educational issues, and some are even being recruited as educational researchers. These developments promise much closer 
and mutually informed collaborations between neuroscientists and educators than ever before, and such developments can only be considered to be a good thing.

True collaboration in seeking common and expanded understandings, whether between individual researchers or between different fields of study, presupposes contributions and movement in both directions. Intense efforts must be made on both sides to understand the presuppositions and perspectives of the other. Agreement is not a prerequisite. Achieving common and expanded understandings on issues pertaining to and informed by both education and neuroscience is a goal to strive for-and all the better if achieved.

In this light, some educational researchers, amongst which I count myself as one, are incorporating methods of cognitive neuroscience in their research, and more specifically in my case, electroencephalography (EEG). I am not using this new methodology for the purpose of conducting cognitive neuroscience. As my focus is placed primarily on educational issues, I consider myself involved in educational neuroscience.

EEG is a clear method of choice for educational researchers who would like to augment their research with quantifiable observations of brain and brain behavior. One reason for this is that EEG is amongst the least expensive of brain imaging technologies. Another is that EEG is quite adept for capturing the dynamics of thought in action. It offers temporal resolutions at the speed of thought and places fewer spatial constraints on learners than other methods. Furthermore, as evidence of increasing confidence in both the reliability and robustness of the method, many "turnkey" acquisition and analysis systems are now readily available, placing fewer technical burdens on researchers using these systems.

Although my program of research is in education, successfully incorporating EEG presupposes expertise with and requires effective use of this methodology. This requires acquisition, analysis, and interpretation of voltage potentials from electrical activity generated from within brains, and recorded from scalps, of sentient and thinking beings. This in turn presupposes basic knowledge of signal processing and mathematical modeling. Such skills are not typically offered to graduate students in education. They must be, if education is to successfully incorporate these methods.

In a recent feature article in the Educational Researcher, Eisenhart and DeHaan (2005) emphasize the importance of preparing doctoral students in education for interdisciplinary studies spanning the natural and social sciences: "Drawing on developments in the fields of neuroscience, sociology of natural science, and the learning sciences, the authors argue for an approach to doctoral training that is consistent with a broad definition of scientifically based research" (p. 3).

In accord with Eisenhart and DeHaan (2005), and with particular emphasis on EEG, this paper discussion reports and reflects on the design, approval, implementation, conduct, and reception of a new graduate course, entitled "Educational Neuroscience: Background, Theories, and Methods," offered for the first time in the 2005-2006 academic year. An outline for the most recent offering this course is appended at the end of this paper.

\section{Perspectives or Theoretical Framework}

Educational neuroscience is basically viewed here as a new area of educational research, not so much for building a bridge between the neurosciences and education, as filling a gap. In filling this gap, foundations for such a bridge can be put in place. Educational neuroscience prioritizes learners. It is rightly informed by, but should not be geared toward identifying neural mechanisms underlying or accounting for cognitive behavior. Such is the task of cognitive, not educational, neuroscience.

Accordingly, differences between educational and cognitive neuroscience can be exemplified by the latter's quandaries regarding the function of consciousness and how it can possibly arise from the coordinated activity of neural assemblies. Educational neuroscience, on the other hand, as with 
education generally, takes the reality and utility of consciousness as given: something to work with, not something to explain, or worse, to explain away.

Perhaps the major area of potential overlap and common interest between cognitive and educational neuroscience are cognitive and educational psychology, respectively. Both have been engaged, from various philosophical perspectives, in developing models of cognition and learning. Both are concerned with identifying and establishing reliable and valid correlations between these models and brain behavior. Ergo, there is clear potential for middle ground between these disciplines, despite their differences.

Be that as it may, an important dose of skepticism seems warranted. Important questions to consider concern why various aspects of brain and brain behavior should be of any interest whatsoever to educational researchers. Byrnes (2001) has served as an excellent text for this course, in that he specifically addresses these kinds of questions up front. A central theme throughout the course to this point has been to consider various ways in which various theories, methods, and results of cognitive neuroscience can serve to augment and inform educational research.

\section{Methods, Techniques, or Modes of Inquiry}

This course was originally designed as being geared toward laboratory projects, and therefore class enrollment was limited to 12 students. In hindsight, this may have been a mistake, at least for the first offering. It took more time than anticipated to populate the lab with the necessary equipment and expertise for this purpose. However, only seven students enrolled. Had the emphasis on the initial offering remained at a more conceptual level, enrollment may have been higher, and there would have been lower expectations on the part of those who did enroll to partake in hands on projects. Although there were no prerequisites aside from being a graduate student in education, admission was left to the discretion of the author/instructor, which is based on levels of student interest, enthusiasm, background knowledge, and experience.

A text establishing relevance and providing orientation for the class is Byrnes (2001). Readings from this text have been supplemented by articles, some assigned to the whole class and others assigned with consideration given to the particular interests of individual students. These articles were drawn from, but not restricted to those listed under "Additional Course Readings" in the references.

The traditional graduate seminar format was implemented for the background and theory components of the course. Here the literary and pedagogical emphasis has been four-fold: reading, reflecting upon, summarizing, and discussing assigned readings. Throughout the first part of the course, the class remained focused on questions pertaining to experimental design, and its relation between theory and method.

Eight of the 13 weeks of this course were initially dedicated to methodology, with two of these focusing on general and more specific matters of experimental design, with the remaining six weeks focused on participating and contributing in various ways to pilot studies conducted by the author in the areas of mathematics anxiety and mathematical understanding. In the most recent offering of this course, there will be much greater emphasis on "hands-on" applications in educational neuroscience.

\section{Laboratory team projects}

Depending on their respective interests, and in negotiation and with guidance from the instructor, the initial intent of the course, however, was for students to form laboratory teams and assigned projects providing hands-on experience with methods of educational neuroscience. Sample projects for the current course offering may include: 
Insight Phenomenon: Using electroencephalography (EEG), attempt to replicate (Jung-Beeman, et al, 2004) findings of a sudden burst of high-frequency (gamma band) neural activity beginning .3 seconds prior to insight solutions in the right hemisphere superior anterior temporal cortex of team members engaged in problem solving tasks. Results analyzed and critiqued in accord with other works (e.g., Banks, 2002).

Comprehension Strategies: Using eye-tracking, attempt to replicate (Hegarty, et al, 1995) findings that comprehension strategies of team members as successful and unsuccessful problem solvers can be identified by eye-fixations in reading/re-reading the problem.

Brain Control: Using neurofeedback, attempt to replicate (Guger, et al, 2003 or Vernon, et al, 2003) findings that with a relatively small amount of training, team members can learn to mentally control the level of electrically induced brain wave frequencies, and thereby, to some extent, control a brain-computer interface and improve cognitive performance.

These laboratory team projects, as has been the case with the author's pilot studies, would be divided into four stages: data acquisition; analysis; interpretation and conclusions; and subsequent class presentation and discussion of results.

\section{Practical inquiry}

A focal point for following up on this paper will be on lessons learned through the launching of this course. How effective has it been? What kinds of results have been obtained? What complications have arisen? Has it been achieving its objectives? What changes will contribute to the course being more effective in future offerings? What are the central formative and most lasting experiences of the students? Specific answers to these questions are still being assessed. However, after having offered this course twice now, in Spring, 2006, and Summer, 2007, there have been very strong positive responses across the board based on the course evaluations of the students who have taken it.

\section{Data Sources or Evidence}

The educational neuroscience laboratory offers a full suite of psychophysiological measures for detailed and comprehensive research into functional correlates between cognition and various aspects of embodied behavior. Orbiting this comprehensive system of observational methods around a computerassisted learning environment allows for flexibility of experimental design and delivery, and data integration and analyses.

Students working with the author have guided and supervised access to this laboratory, and for those students providing ethical clearance for participation in his pilot studies, audiovisual psychophysiological recordings of their contributions will be presented.

\section{Results and/or Conclusions/Points of View}

It is anticipated that the launching and continued offerings of this course will provide a wide spectrum of affective and intellectual experiences for the students and instructor-these experiences variously ranging from frustration, confusion, and skepticism to excitement, illumination, and potentially profound achievements.

Collectively, these results are providing insights as to what kinds of expectations and objectives for future offerings of this course are realistic and achievable, and what kinds of prerequisite and additional resources and/or support systems are required to help meet them. 


\section{Educational or Scientific Importance}

The importance of this course is to serve the immediate needs and long-term goals of educational neuroscience. Filling the gap between education and the neurosciences to better inform educational practice in an evidence-based and scientifically-based manner is in the public interest. Launching this course is a small step, but one with this end in view.

\section{Acknowledgement s}

A previous version of this paper was submitted and presented to the Brain, Neuroscience, and Education SIG of the American Educational Research Association (AERA) Conference, April 8, 2006.

\section{References}

Campbell, S. R. with the ENL Group (2007). The ENGRAMMETRON: Establishing an educational neuroscience laboratory. Simon Fraser University Educational Review, 1, 17-29.

Eisenhart, M., \& DeHaan, R. L. (2005). Doctoral preparation of scientifically based education researchers. Educational Researcher, 34(4): 3-13.

McNiff, J., with Whitehead, J. (2002). Action research: Principles and practice. London; New York: Routledge Falmer.

NRC (National Research Council) (2000). How people learn: Brain, mind, experience and school. Washington, DC: National Academy Press.

NRC (National Research Council) (2002). Scientific research in education. Washington, DC: National Academy Press.

Richardson, V. (1994). Conducting research on practice. Educational Researcher, 23(5); 5-10.

\section{Background}

Brazier, M. A. B. (1962). "The analysis of brain waves." Scientific American 206: 142-153.

Berninger, V. W. and D. Corina (1998). "Making cognitive neuroscience educationally relevant: Creating bidirectional collaborations between educational psychology and cognitive neuroscience." Educational Psychology Review 10(3): 343-354.

Bruer, J. T. (1997). "Education and the brain: A bridge too far." Educational Researcher 26(8): 4-16.

Bruer, J. T. (1999). "In Search of Brain-Based Education." Phi Delta Kappan 80(9): 648-657.

Byrnes, J. P. (2001). Minds, brains, and learning: Understanding the psychological and educational relevance of neuroscientific research. New York: The Guilford Press.

Caton, R. (1875). "The electrical currents of the brain." British Medical Journal 2: 278.

Dorus, S., E. J. Vallender, et al. (2004). "Accelerated evolution of nervous system genes in the origin of Homo sapiens." Cell 119: 1027-1040.

Geake, J. G. (2004). "Cognitive neuroscience and education: two-way traffic or one-way street?" Westminster Studies in Education 27(1): 87-98.

Geake, J. and P. Cooper (2003). "Cognitive neuroscience: Implications for education?" Westminster Studies in Education 26(1): 7-20.

Glass, A. and R. J. Riding (1999). "EEG differences and cognitive style." Biological Psychology 51(1): 2341.

Goswami, U. (2004). "Neuroscience and education." British Journal of Educational Psychology 74(1): 1-14. 
Hayward, R. (2001). "The Tortoise and the Love-Machine: Grey Walter and the Politics of Electroencephalography." Science in Context 14(4): 615-641.

Kay, L. E. (2001). "From Logical Neurons to Poetic Embodiments of Mind: Warren S. McCulloch's Project in Neuroscience." Science in Context 14(4): 591-614.

Kember, D. (2000). Action learning and action research: improving the quality of teaching and learning. London: Kogan Page.

Lindsley, D. B. (1936). "Brain potentials in children and adults." Science 84(2102): 354.

Maxwell, J. A. (2004). "Causal explanation, qualitative research, and scientific inquiry in education." Educational Researcher 33(2): 3-11.

Mayer, R. E. (1998). "Does the brain have a place in educational psychology?" Educational Psychology Review 10(4): 389-396.

Pribram, K. H. (1962). Interrelations of psychology and the neurological disciplines. Psychology: A study of a science, Volume 4. Biologically oriented fields: Their place in psychology and in biological science. S. Koch. New York, NY, US, McGraw-Hill: 119-157.

Reese, H. W. (2001). "Some recurrent issues in the history of behavioral sciences." Behavior Analyst 24(2): 227-239.

Walter, W. G. (1967). "Traps, Tricks and Triumps in EEG - 1936-1966." Electroencephalography and Clinical Neurophysiology 22(4): 393.

\section{Theoretical Issues}

Engel, A. K., P. Fries, et al. (2001). "Dynamic predictions: Oscillations and synchrony in top-down processing." Nature Reviews Neuroscience 2(10): 704-716.

David, O., L. Garnero, et al. (2001). A New Approach to the MEG/EEG Inverse Problem for the Recovery of Cortical Phase-Synchrony. Information Processing in Medical Imaging: 17th International Conference, IPMI 2001, June 18-22, 2001, Proceedings, Davis, CA, USA, Springer-Verlag GmbH.

David, O., L. Garnero, et al. (2002). "Estimation of neural dynamics from MEG/EEG cortical current density maps: Application to the reconstruction of large-scale cortical synchrony." IEEE Transactions on Biomedical Engineering 49(9): 975-987.

Dehaene, S., G. Dehaene-Lambertz, et al. (1998). "Abstract representations of numbers in the animal and human brain." Trends in Neurosciences 21(8): 355-361.

Erdi, P. (2000). "On the 'dynamic brain' metaphor." Brain \& Mind 1(1): 119-145.

Freeman, W. J. (2004). "Origin, structure, and role of background EEG activity. Part 1. Analytic amplitude." Clinical Neurophysiology 115(9): 2077-2088.

Freeman, W. J. (2004). "Origin, structure, and role of background EEG activity. Part 2. Analytic phase." Clinical Neurophysiology 115(9): 2089-2107.

Kunnen, E. S. and H. A. Bosma (2000). "Development of meaning making: A dynamic systems approach." New Ideas in Psychology 18(1): 57-82.

Lachaux, J.-P., A. Lutz, et al. (2002). "Estimating the time-course of coherence between single-trial brain signals: an introduction to wavelet coherence." Neurophysiologie Clinique/Clinical Neurophysiology 32(3): 157-174.

Makeig, S., S. Debener, et al. (2004). "Mining event-related brain dynamics." Trends in Cognitive Sciences 8(5): 204-210.

Makeig, S. (2002). "Event-related brain dynamics - unifying brain electrophysiology." Trends in Neurosciences 25(8): 390.

Michel, C. M., M. M. Murray, et al. (2004). "EEG source imaging." Clinical Neurophysiology 115(10): 2195-2222.

National Research Council (NRC) (2002). Scientific Research in Education. Washington, DC: National Academy Press. 
Ollikainen, J. O., M. Vauhkonen, et al. (1999). "Effects of local skull inhomogeneities on EEG source estimation." Medical Engineering \& Physics 21(3): 143-154.

Penny, W. D., S. J. Kiebel, et al. (2002). "Event-related brain dynamics." Trends in Neurosciences 25(8): 387-389.

Rubin, M. A. (1938). "The distribution of the alpha rhythm over the cerbral cortex of normal man." Journal of Neurophysiology 1: 313-323.

Varela, F. J. (1995). "Resonant cell assemblies: a new approach to cognitive functions and neuronal synchrony." Biological Research 28(1): 81-95.

Varela, F., J. P. Lachaux, et al. (2001). "The brainweb: Phase synchronization and large-scale integration." Nature Reviews Neuroscience 2(4): 229-239.

\section{Methodological Issues}

Banks, W. P. (2002). "On Timing Relations between Brain and World." Consciousness and Cognition 11(2): 141-3.

Barlow, J. S. C., A. Kamp, et al. (1974). "EEG instrumentation standards: Report of the committee on EEG instrumentation standards of the international federation of societies for electroencephalography and clinical neurophysiology." Electroencephalography and Clinical Neurophysiology 37(5): 549-553.

Beaulieu, A. (2002). "A Space for Measuring Mind and Brain: Interdisciplinarity and Digital Tools in the Development of Brain Mapping and Functional Imaging, 1980-1990." Brain and Cognition 49(1): 13-33.

Darvas, F., D. Pantazis, et al. (2004). "Mapping human brain function with MEG and EEG: methods and validation " NEUROIMAGE 23(Special Issue): S289-S299 Suppl. 1.

Delorme, A. and S. Makeig (in press). "EEGLAB: an open source toolbox for analysis of single-trial EEG dynamics including independent component analysis." Journal of Neuroscience Methods.

Duchowski, A. T. (2003). Eye-tracking methodology: Theory and practice, Springer.

Egner, T., T. F. Zech, et al. (2004). "The effects of neurofeedback training on the spectral topography of the electroencephalogram." Clinical Neurophysiology 115(11): 2452-2460.

Guger, C., G. Edlinger, et al. (2003). "How many people are able to operate an EEG-based braincomputer interface (BCI)?" Neural Systems and Rehabilitation Engineering, IEEE Transactions on [see also IEEE Trans. on Rehabilitation Engineering 11(2): 145-147.

Hagemann, D. (2004). "Individual differences in anterior EEG asymmetry: methodological problems and solutions." Biological Psychology 67(1-2): 157-182.

Hegarty, M., R. E. Mayer, et al. (1995). "Comprehension of arithmetic word problems: A comparison of successful and unsuccessful problem solvers." Journal of Educational Psychology 87(1): 18-32.

Jasper, H. H. (1958). "The ten-twenty electrode system of the International Federation." Electroencephalography and Clinical Neurophysiology 10:371-375.

Jung-Beeman, M. J., E. M. Bowden, et al. (2004). "Neural Activity When People Solve Verbal Problems with Insight." PLOS BIOLOGY 2(4): 500-510.

Lachaux, J. P., E. Rodriguez, et al. (1999). "Measuring phase synchrony in brain signals." Human Brain Mapping 8(4): 194-208.

Le Van Quyen, M., J. Foucher, et al. (2001). "Comparison of Hilbert transform and wavelet methods for the analysis of neuronal synchrony." Journal of Neuroscience Methods 111(2): 83-98.

Talukder, A., J.-M. Morookian, et al. (2005). "Eye-tracking architecture for biometrics and remote monitoring." Applied Optics 44(5): 693-700.

Teplan, M. (2002). "Fundamentals of EEG measurement." Measurement Science Review 2(2): 1-11.

Vernon, D., T. Egner, et al. (2003). "The effect of training distinct neurofeedback protocols on aspects of cognitive performance." International Journal of Psychophysiology 47(1): 75-85. 
Winn, W. (2003). "Research Methods and Types of Evidence for Research in Educational Technology." Educational Psychology Review 15(4): 367-373.

Reva, N. V. and L. I. Aftanas (2004). "The coincidence between late non-phase-locked gamma synchronization response and saccadic eye movements." International Journal of Psychophysiology 51(3): 215-222.

\section{About the Author}

Stephen Campbell is a member of the Faculty of Education, Simon Fraser University. He can be reached at sencael@sfu.ca. iChat: sencael@mac.com. Further information about this program and research is available at www.engrammetron.net. 


\section{SIMON FRASER UNIVERSITY EDUCATION 907-5}

(Cat. \#16732)

\section{EDUCATIONAL NEUROSCIENCE: \\ THEORIES, METHODS, AND APPLICATIONS \\ Summer Semester, 2008}

Day/Time/Room: Thursday, 4:30PM-9:20PM, in the ENGRAMMETRON

\begin{tabular}{|l|r|}
\hline Instructor: & Stephen R. Campbell, Ph.D. \\
\hline Office: & EDB 8643 \\
\hline Office Hours: & by appointment \\
\hline Voice-mail: & $1-604-291-3630$ \\
\hline E-mail: & sencael@sfu.ca \\
\hline
\end{tabular}

Course Description

This course provides a "hands on" overview of a potentially foundational new area of educational research. It will introduce new quantitative perspectives to areas of qualitative research in education concerned with cognition, affect, and learning. The course has no prerequisites, but is aimed toward graduate students in education, psychology, kinesiology, and biomedical engineering.

\section{Course Requirements}


In addition to attendance and participation in discussion, there will be five 1-page, ( 150-250 word), "discussion paper" assignments (50\%), students in groups will design, conduct, analyze, interpret, and write up a pilot project experiment in educational neuroscience chosen from a list of possibilities provided by the instructor $(50 \%)$. Sample possibilities will be provided.

\section{Course Text}

Byrnes, J. P. (2001). Minds, brains, and learning: Understanding the psychological and educational relevance of neuroscientific research. The Guilford Press.

ISBN: 1572306521

\section{Conduct of the Seminar}

Participants will be expected to read, reflect upon, write about, and discuss approximately 30 to 50 pages of primary and/or secondary literature per week. Readings will be drawn from, but optional readings not necessarily restricted to, the required texts. Individual exploration, research, and exegesis of various threads of thought germane to the focus of the seminar will be encouraged.

\section{Final Outline}

Some slight modifications, corrections, or additions to this outline may be forthcoming at the beginning of the first class.

\section{Enrollment Limit}

Because this is a laboratory-based course, and due to the logistics involved, course enrollment will is limited to 12 and by permission from the instructor. 
COURSE SCHEDULE:

\begin{tabular}{|c|c|}
\hline DATE & TOPIC \\
\hline Week 1 & $\begin{array}{l}\text { Background and Overview of the Course } \\
\text { Tour of the ENGRAMMETRON }\end{array}$ \\
\hline Week 2 & $\begin{array}{l}\text { Theoretical Issues in Educational Neuroscience: Part } 1 \\
\text { From Psychophysiology to Cognitive Neuroscience and } \\
\text { "Brain-Based Learning" }\end{array}$ \\
\hline Week 3 & $\begin{array}{l}\text { Theoretical Issues in Educational Neuroscience: Part } 2 \\
\text { Comparing Cognitive and Educational Neuroscience }\end{array}$ \\
\hline Week 4 & $\begin{array}{l}\text { Methodological Issues in Educational Neuroscience: Part } 1 \\
\text { Overview of ENGRAMMETRON Systems and Software }\end{array}$ \\
\hline Week 5 & $\begin{array}{l}\text { Methodological Issues in Educational Neuroscience: Part } 2 \\
\text { Introduction to Signal Processing and Brain Imaging }\end{array}$ \\
\hline
\end{tabular}




\begin{tabular}{|c|c|}
\hline Week 6 & $\begin{array}{l}\text { Methodological Issues in Educational Neuroscience: Part } 3 \\
\text { Experimental Design }\end{array}$ \\
\hline Week 7 & $\begin{array}{l}\text { Applications in Educational Neuroscience: Part } 1 \\
\text { Data Acquisition in the ENGRAMMETRON }\end{array}$ \\
\hline Week 8 & $\begin{array}{l}\text { Applications in Educational Neuroscience: Part } 2 \\
\text { Data Acquisition and Analysis in the ENGRAMMETRON }\end{array}$ \\
\hline Week 9 & $\begin{array}{l}\text { Applications in Educational Neuroscience: Part } 3 \\
\text { Data Analysis and Interpretation in the ENGRAMMETRON }\end{array}$ \\
\hline Week 10 & $\begin{array}{l}\text { Applications in Educational Neuroscience: Part } 4 \\
\text { Data Interpretation in the ENGRAMMETRON }\end{array}$ \\
\hline Weeks 11-13 & Course Project Presentations and Discussions \\
\hline
\end{tabular}

